\title{
Representação cultural e modernidade
}

Belmira Magalhães ${ }^{1}$

Gostaria de começar este artigo citando um trecho extraído do livro de Renato Ortiz (1994), Mundialização e cultura. Diz o texto:

O Ford-Fiesta é montado em Valência (Espanha), mas os vidros vêm do Canadá; o carburador da Itália; os radiadores da Austria; os cilindros, as baterias e a ignição da Inglaterra; o pistão da Alemanba, e o eixo de transmissão da França.(p.108)

Como pensar em representação cultural, termo ligado essencialmente à idéia de povo e nacionalidade, em um tempo de globalizaçào? Pode-se continuar usando os mesmos parâmetros que orientaram as análises sobre esse tema até o presente, ou se faz necessário buscar novas formas que permitam entender o processo cultural do mundo contemporâneo?

Iniciemos com um olhar para o passado próximo $\neg$ aqui é importante que eu esclareça que minha análise se aterá à expressào cultural literária, nào porque considere ser a mais importante, mas por ser aquela em que transito melhor. Voltemos nossas atençòes para o início da modernidade, isto é, ao período de surgimento e implantaçào do sistema capitalista. A modernidade é a expressão de um tempo que se baseia fundamentalmente na racionalidade humana. Para esse momento histórico, o gênero humano, por ser racional, necessita fazer uso pleno dessa capacidade nas tomadas de decisòes, desde aquelas relativas ao seu cotidiano até às indutoras de mudanças sociais ${ }^{2}$. Para a grande autoridade do racionalismo que foi Kant, a utilizaçào da razào é a única forma de se chegar à verdade, à moral, um imperativo ético, único caminho para a justiça.

\footnotetext{
"Prof" Dra do Programa de Pós-Graduação em Lingǘstica e Literatura Brasileira da UF.AL. ¿Para a discussão sobre a instauração da sociedade moderna, ver Zaidan, 1989, Berman, 1990 e Lukács, s/d.
} 
A sociedade que surge com a ascensão da burguesia ao poder instaura a possibilidade, pela primeira vez na história humana, da condução consciente pelo homem de seu próprio destino.

Nossa visão da vida moderna tende a se bifurcar em dois niveis, o material e o espiritual. [...] Esse dualismo, generalizado na cultura contemporânea, dificulta nossa apreensão de um dos fatos mais marcantes da vida moderna: a fusão de suas forças materiais e espirituais, a interdependência entre o individuo e o ambiente moderno. (Berman,1990:129)

A burguesia se coloca como sujeito da história ao se realizar politicamente como classe, consolidando a divisão entre o cidadão e o indivíduo. Este tem como característica o egoísmo, a visào particularizada; aquele representa a comunhào, a coletividade. Homens livres, independentes, individuais, que, no jogo de um mercado também livre, possuem a liberdade de vender sua força de trabalho, através de um contrato que lhes possibilita a garantia da lei.

Apresenta-se então a possibilidade de instauração da individualidade, entendida agora como personalidade individualizada que, apesar das amarras do social, se torna capaz de decidir, como veremos no decorrer do artigo, pelo menos sobre seu destino amoroso. Individualidade contraditória, marca principal da modernidade, pois expressa, ao mesmo tempo, a exaltação do indivíduo enquanto ser que escolhe e o limite de possibilidades de escolha para cada grupo social.

No Romantismo, a importância do indivíduo alcança, do ponto de vista histórico-literário, seu ponto culminante. No romance de José de Alencar, Senhora (1975), uma das expressòes do romantismo no Brasil, o autor destaca a importância e contraditoriedade da individualidade, exaltando, ao mesmo tempo, a impossibilidade de controle total sobre ela e a necessidade de submissão em que alguns seres são impelidos a viver, principalmente pelo lugar que ocupam na estrutura social:

Vendi-lhe um marido, tem-no a sua disposição como dona e senhora que é. O que porém não the vendi foi minh'alma, meu caracter, a minha individualidade; porque essa não é dado ao homem alheá-la de si, e a senhora sabia perfeitamente que não podia jamais adquiri-la a preşo d'ouro. (210)

Essa divisão do ser, que impossibilita sua completude, permite contraditoriamente ao homem se resguardar e se transformar. Há sempre o 
relacionamento ativo do sujeito com o mundo. Regida, no movimento romântico, quase sempre por forças sobrẹnaturais e acasos, a individualidade está presente na busca de seu caminho, sempre tortuoso, conflitante, mas possível de ser dirigido. Essa compreensão de que pode transgredir o já existente e criar o novo capacita o ser humano com a possibilidade de dirigir seu destino, dentro das condições objetivas em dada sociabilidade.

Como expressão cultural de um momento da história do gênero humano, o romantismo não poderia deixar de refletir sobre a própria contraditoriedade da sociedade: ao tempo que reforça e exalta a existência de forças exteriores ao mundo humano na conduçào de seu destino, afirmando, portanto, a universalidade e perenidade de um determinado ser histórico, o romantismo expressa, embora de forma tênue e limitada, a possibilidade de condução dos destinos por màos humanas, logo, falíveis, mas sempre transformadoras.

Aludindo ao romantismo, procuramos salientar a intrínseca relaçào entre a materialidade, isto é, as formas de viver, e a expressão desse viver, representadas pelo movimento cultural de cada tempo e espaço histórico. Desde já deve ficar esclarecido que essa representação nào se refere ao espelhamento da realidade, mas à reflexào sobre um momento histórico, que, no caso da arte, implica necessariamente criaçào de algo novo, capaz, inclusive, de influenciar a própria materialidade. Segundo Lukács (1981):

A eficácia da grande arte consiste precisamente no fato de que o novo, o original, o significativo obtém a vitória sobre as velhas experiências do sujeito receptivo. Justamente aqui se manifesta aquela ampliação e aquele aprofundamento das experiências que é causado pelo mundo representado na obra. (p.199)

Com o desenvolvimento da modernidade, a exaltaçào da razào continuou a ser o marco de entendimento desse período. A ciência e a técnica, expressòes primeiras da racionalidade, se desenvolvem num ritmo aparentemente sem limite, mas a ingenuidade dos primeiros tempos modernos, que antevia como consequêencia direta desse desenvolvimento uma sociedade mais justa, foi abalada pelas constantes visòes das contradiçòes sociais exibidas em praça pública.

As revoluçòes operárias de 1848, a comuna de Paris em 1871, marcam, historicamente, o fim do idilio entre a burguesia que exaltava as conquistas do cidadào e o homem miserável que habitava as fábricas e as ruas. 
Baudelaire, mais que um fotógrafo, - a fotografia foi uma grande conquista da humanidade nesse período, - traça o retrato perfeito dessa realidade contraditória, no texto Os olhos dos pobres, que mostra a efervescência dos cafés parisienses no início do século, repletos de gente alegre, bonita e nutrida, e a miséria que de longe se encanta com as luzes:

Plantados diante de nós, na calçada, um bravo bomem de seus quarenta anos, de rosto cansado, barba grisalba, trazia pela mão um menino e no outro braço um pequeno ser ainda muito frágil para andar. todos em farrapos. [...] Essa gente é insuportável, com seus olhos abertos como porta de cocheira! Não poderia pedir ao maître para os tirar daqui? (84/85)

Ao captar as contradições culturais, o artista procura desvendar os conflitos de sua época. A lírica moderna expressa a angústia, a inquietude do homem e, para isso, nào há necessidade de rótulos que conduzam à classificaçào das artes como engajadas ou conservadoras. Estas, enquanto arte, terào que expressar a humanização, que significa o processo contínuo e ininterrupto de afastamento da lógica da natureza e inserção crescente na processualidade histórica.

Acabam-se as fronteiras, como salienta Friedrich (1978), entre o belo e o feio, entre a proximidade e a distância, entre o céu e a terra. Todas essas antigas oposiçòes serão tratadas como pertencentes ao mesmo mundo, a palavra transformar domina o poeta moderno. Transformar a própria poesia, libertá-la das formas que a aprisionam, fazer coabitarem o feio e o belo, transpor distâncias impossíveis no mundo real, fazer da alegria uma dor e, desta, a possibilidade de felicidade e, acima de tudo, criar um ser independente de seu modelo divino, como queria a tradição medieval.

O ser único e o universal se encontram no mundo; o espaço corpóreo e o espaço universal sào partes da mesma totalidade. Ferreira Gullar em Poema sujo (1970), nos apresenta, ao mesmo tempo, o limite espacial do ser, o filho de alguém, o maranhense, a classe social e o representante da humanidade:

Meu corpo de 1.70 que é meu tamanho no mundo meu corpo feito de água e inga

[...] 
mas sobretudo meu

$\begin{array}{cc} & \begin{array}{c}\text { corpo } \\ \text { nordestino }\end{array} \\ \text { mais que isso } & \\ \text { mais que isso } & \text { ferreirense } \\ & \text { newtoense } \\ & \text { alzirense } \\ {[. .]} & \\ \text { pulsando bá } 45 \text { anos } \\ {[. . .]}\end{array}$

$(23 / 24)$

Na verdade, as classes perigosas que necessitavam ser controladas para evitar seus descaminhos são vistas agora pelo artista como as únicas capazes de transformar o mundo. A possibilidade de uma sociedade mais justa é entendida como um processo a ser realizado pela razão, através de um trabalho árduo de conscientização das massas, pois, como nos ensina Baudrillard (1877):

Há uma desigualdade que a democracia não destrói, pois a riqueqa subsiste e com ela a propriedade e com a propriedade as inumeras causas de desigualdade que se encontram na natureza bumana (p.157-58)

Dessa forma, a arte passa a expressar essa nova perspectiva de mudança, e Brecht (1977) nos alerta através de seus versos:

Contaram-me que em New York

numa esquina da ma vinte e três com a Broadway

nos meses de inverno, há um bomem todas as noites

que rogando aos transeuntes

proura um refugio para os desamparados que ali se reunem

$[\ldots]$

Mas assim o mundo não muda,

as relacoues entre os homens não se tornam melhores

Não é esta a forma de tornar mais unta a era da explorajão

(p.59)

LEITURA 
A revolução está na ordem do dia tanto para ser combatida como para ser exaltada. Há os que defendem a impossibilidade de combate radical à desigualdade, por ser natural, como vimos em Baudrillard, ou como em Victor Hugo, que afirma, olhando para a modernidade e as transformações operadas no consumo, que o luxo é necessário, a desigualdade é natural, no entanto, não se deve ostentar, nem tirar o pão do pobre.

Caminhemos, agora, com Paulo Honório, personagem de Graciliano Ramos em São Bernardo, latifundiário que percebe, através da mulher, Madalena, as desigualdades sociais, mas não consegue agir, por ser, como ele mesmo reconhece, de uma profissão que o impede. Na verdade, Paulo Honório pertence a uma classe que não está historicamente determinada a promover mudanças estruturais que acabem com os próprios privilégios.

Já Fabiano e sinha Vitória, protagonistas de Vidas secas, romance do mesmo autor, são deixados no meio do caminho pelo narrador para, quem sabe, se transformarem em trabalhadores nas fábricas de São Paulo, incorporando-se à classe operária e, aí sim, como preconizava o ideal revolucionário, que norteia as açòes na modernidade, tornarem-se agentes transformadores daquela realidade social baseada no conflito de classes.

E, para deixarmos a modernidade e, enfim, entrarmos no que se chama hoje pós-modernidade - sem ainda definirmos o que realmente vem a ser isso retornemos a Brecht (1977) e a seu canto de esperança que preconiza a possibilidade de desmoronamento do mundo dos privilégios:

\author{
Desconfiai do mais trivial, \\ na aparência singelo. \\ E examinai, sobretudo, o que parece habitual. \\ Suplicamos expressamente: \\ não aceiteis o que é de hábito \\ como coisa natural, \\ pois em tempos de desordem sangrenta, \\ de confusão organizada, \\ de arbilrariedade consiciente, \\ de bumanidade desumanizada, \\ nada deve parecer natural \\ nada deve parecer impossivel de mudar: (p. 45)
}

O muro alemão, símbolo de uma época, foi transformado em souvenir e a razão foi colocada sob suspeita, por ser instrumento para a manutenção do poder. 
Michel Zaidam (1992), seguindo Habermas, afirma que a modernidade social $e ́$ responsável pela racionalidade da economia e do Estado, gerando subsistemas de ação instrumental que operam automaticamente sobre os individuos, independente de suas vontades(25), aprisionandolhes a lógica do poder instituído.

Surge entào a contemporaneidade, que pretende ser ao mesmo tempo continuidade e substituiçào dos tempos modernos.

Os contrários cada vez mais se confundem nessa nova era, pois, ao mesmo tempo que há a emergência de uma sociedade global, com a mundialização da cultura se revelando através do mercado e do consumo, há uma exaltação da diversidade, do diferente, da fragilidade, da desrazào. Quanto maior a racionalidade exigida no processo de fabricaçào de um automóvel, feito para além das nacionalidades, mais o grito de nào à coletivizaçào e o culto aos próprios anjos e ao próprio corpo.

A realidade objetiva é substituída pelas diversas representações que acabam se transformando na própria objetividade. Segundo Zaidam (1989), o real é subsumido a um processo de significią̧ão sem referente, auto-referenciado.(p.21)

Para Renato Ortiz (1994), a emergência dessa época centrípeta, na qual fica difícil localizar a centralidade das coisas, não significa ausência de poder, ou partilha em termos democráticos. Pelo contrário, as relaçòes de autoridade, ao se tornarem descentralizadas, adquirem outra abrangência.

A civilizaçào mundial, ao nos situar em outro patamar da história, carrega consigo desafios, esperanças e utopias, mas engendra também novas formas de dominação. Entendê-las é refletir sobre as raízes de nossa contemporaneidade. Há uma politização do todo social, cada ato singular adquire a mesma importância dos atos coletivos ou de grupos, temos a banalizaçào do político que gera o descentramento do politicio e a redefiniçáo da política e seus objetivos (Evangelista, 1992:26).

Representando esse movimento, os textos romanescos apresentam-se sob a forma de intertexto, construídos como um mosaico, que só se relacionam naquele lugar e momento, não havendo nada sólido que ligue as partes, apenas a velocidade supersônica da informaçào.

Estar em dia hoje não é estudar profundamente autores e correntes para criticá-los, mas estar na onda do último best-seller, conhecer mais um ritmo de dança, saber o nome do último filósofo em moda e citá-lo com uma certa propriedade. É, finalmente, estar sempre ligado, isto é, manter sempre ligada a tomada do computador ou dos contatos transcendentais, das várias formas possíveis de se conseguir esse estado de espírito, e considerar todos os que não agem dessa forma como ultrapassados.

No conto V'ai, de Ivan Ângelo (1994), o autor apresenta uma fábula comum sobre um homem que está perdendo a namorada para outro. Eu sei ver as qualidades 
de uma pessoa, mesmo quando é um homem que vai roubar minha namorada. Roubar não: ganhar (12). Todo o texto se constrói para mostrar ao leitor, através do personagem perdedor, uma comparaçào entre dois homens em disputa; no entanto, por trás da aparência textual, é realizada uma comparação entre dois momentos históricos distintos.

O quadro que se apresenta é o de dois mundos em confronto, duas formas de viver, que têm o mesmo espaço histórico de convivência, tendo, por isso, necessariamente, de se interligarem:

1- O mundo da era tecnológica, na velocidade supersônica, no vigor físico, na beleza, na ação e realidade virtuais, que moldam de forma integral o comportamento de homens e mulheres, onde o sujeito histórico é reduzido a um mero feixe de sensą̧ões hedonistas. (Evangelista,1992:25). Baseado nesses critérios é que o narrador perdedor olha para o rival e reconhece suas qualidades:

Compara: Ele dança muito bem. Campeão de natação, anda de bicicleta, é bom de moto, sabe atirar, é uma fera no volante, caça e acha, monta a cavalo, mete o braço, pesca, veleja, mergulba... Não tem companbia melhor (13).

2- Do outro lado, tem-se o mundo criado sob o humanismo, fruto do iluminismo, no qual o homem ainda esperava tornar-se centro de todas as açòes e as idéias eram valorizadas como forma de conduzir a humanidade para um futuro de prosperidade, beleza e comunhão. Como diz o narrador, um mundo em que considerar as pessoas em primeiro lugar não se constituía em defeito; em que o prazer de caminhar é tào importante como o de chegar: Eu troquei a volúpia de chegar rapidinho pelo prazer de estar a caminho, no amor também(14).

São essas duas formas de viver que estão em confronto na pós-modernidade que o autor quer discutir. A forma irônica com a qual enaltece as qualidades do rival mostra que ele pretende preservar as características de centralidade da força humana. Toda a escrita romanesca se encaminha para desvelar a nova lógica de acumulação do capital, evitando assim que ela devore tanto as idéias que não lhe são simpáticas, como os homens e as mulheres, vistos apenas como parte de uma engrenagem que tem a produçào e o consumo como motor.

Enquanto a modernidade se definia como um processo de subjetivação do mundo, a pós-modernidade aparece como anulação das marcas do sujeito, na medida em que o individualiza ao extremo e nega a possibilidade de coletivização que nào tenha como desencadeador o mundo da produção. 
Esta é a discussão que Ivan Ângelo(1994) empreende no conto. Sabe os limites de cada face da questão, por isso inicia o texto dizendo à amada que vá e elogia o rival. Percebe que essa batalha está perdida e passa entào, da ironia, do elogio enganoso, para uma forma mais direta de argumentação, que vai ganhando força na figura do personagem narrador, como se a voz da modernidade assumisse seu lugar reivindicando ser ouvida e gritasse que é preciso redescobrir um mundo capaz de se emocionar com coisas simples, de se indignar com a violência moderna que permite que se use revólver em bolsas, como se fossem batons ou perfumes.

Seguindo esse caminho, o narrador solicita que, pelo menos o leitor/a, continue dando-lhe a oportunidade de esclarecimento, antes de qualquer avaliação final, uma vez que a amada já tem sua decisào de abandoná-lo, e expõe suas qualidades:

Eu seipor exemplo uns poemas de cor, seifazerpapagaio de papel, posso cozinhar uns dois ou três pratos com categoria, tenho certa paciência para ouvir, sei ótima massagem para as costas, mastigo de boca fechada, levo jeito com crianças, conbego umas orquideas, tenho facilidade para descobrir onde colocar umas caricias, minhas coisas são limpas, não bato em mulher (14).

Ivan Ângelo sabe que essas duas visões de mundo estão em confronto e sabe também que não basta pedir para comparar realidades ou relacionamentos; é necessário que a relação entre subjetividade e objetividade seja realizada a partir do conhecimento das possibilidades que os sujeitos têm de interferir na realidade.

Por isso, o narrador, por mais que possa ferir-se, diz à amada que vá, pois espera que a velocidade tão exaltada na contemporaneidade consuma rapidamente esse amor rival, da mesma forma que parte da humanidade espera ver ressurgir, de forma revigorada e contemporânea, as idéias baseadas na centralidade das relaçòes entre homens e mulheres. Precisa-se resgatar a capacidade de indignação que se baseia na crença de que há valores universais que não podem ser abandonados, sob pena de transformaçào, de isolamento completo do ser e perda da generalidade humana. Indignaçào que torna os seres capazes de olhar para os lados e nào se acomodarem com as diferenças sociais, banindo discursos que afirmam a impossibilidade de manter todo mundo no sistema.

E como nosso narrador, que avisou desde o início que razào e emoçào têm de ser conjugadas, formando harmonias, diz ao final do texto para sua amada e para todos os leitores que nada é definitivo: nem histórias de amor, nem negaçào de valores trabalhosamente conquistados pelo gênero humano em sua trajetória. $O$ momento é de refluxo das potencialidades humanas, mas a arte ainda pode antecipar 
e propor mudanças no relacionamento de um casal e no relacionamento em geral e, por isso, a narrativa termina com a possibilidade de transformação sempre presente nas relações históricas: Vai, mas leva a chave para o caso de querer voltar(140).

A subjetividade, através do narrador/personagem, tenta recuperar a força adquirida na modernidade consciente da dificuldade que enfrenta, na medida em que na pós-modernidade há uma busca de apagamento do sujeito, não pela retirada de cena, mas pela sua fragmentação. Por isso, o conto deixa em aberto o futuro, demonstrando que ainda há possibilidades para a subjetividade ocupar seu lugar desde que não abandone as capacidades humanas de raciocinar e se emocionar. 


\section{Referências bibliográticas}

ALENCAR, José de. Senhora. São Paulo: MacGraw-Hill do Brasil, 1975

ÂNGELO, Ivan. O ladrão de sonhos e outras histórias. SãoPaulo: Ática, 1994

BAUDELAIRE, Charles. O spleen de Paris. Rio de Janeiro: Imago, 1995.

BERMAN, Marshall. Tudo que é sólido desmancha no ar: a aventura da modernidade. Sào

Paulo: Ed. Schwarz, 1990

BRECHT, Bertolt. Antologia poética. Rio de Janeiro: EDIL, 1977

EVANGELISTA, Joào. Crise do Marxismo e irracionalismo pós-moderno. São Paulo:Cortez, 1992

GULLAR, Ferreira Poema sıjo. Rio de Janeiro: Civilização Brasileira, 1977.

FRIEDRICH, Hugo. Estrutura da lírica moderna. São Paulo: Duas Cidades, 1978

LUKÁCS, Georg. Teoria do romance. Lisboa: Editorial Presença, [s.d]

LUKÁCS, Georg. Sociologia. Sào Paulo: Ática, 1981

ORTIZ, Renato. Mundialização e Cultura. São Paulo:Bra siliense, 1994

RAMOS, Graciliano. São Bernardo. Sào Paulo: Record, 1995

Vidas Seias. São Paulo: Record, 1995

ZAIDAN, Michel. A crise da raq̃ão histórica. Campinas: Papirus, 1989 